\title{
Breaking Symmetry: Engineering Single-Chain Dimeric Streptavidin as Host for Artificial Metalloenzymes
}

\author{
Shuke Wu, ${ }^{\dagger}{ }^{\dagger}$ Yi Zhou, ${ }^{\dagger}$ Johannes G. Rebelein, ${ }^{\dagger}{ }^{\oplus}$ Miriam Kuhn, Hendrik Mallin, Jingming Zhao, ${ }^{\odot}$
}

Nico V. Igareta, and Thomas R. Ward*(0)

Department of Chemistry, University of Basel, BPR 1096, Mattenstrasse 24a, CH-4058 Basel, Switzerland

\section{Supporting Information}

ABSTRACT: The biotin-streptavidin technology has been extensively exploited to engineer artificial metalloenzymes (ArMs) that catalyze a dozen different reactions. Despite its versatility, the homotetrameric nature of streptavidin (Sav) and the noncooperative binding of biotinylated cofactors impose two limitations on the genetic optimization of ArMs: (i) point mutations are reflected in all four subunits of Sav, and (ii) the noncooperative binding of biotinylated cofactors to Sav may lead to an erosion in the catalytic performance, depending on the cofactor:biotin-binding site ratio. To address these challenges, we report on our efforts to engineer a (monovalent) single-chain dimeric streptavidin (scdSav) as scaffold for Sav-

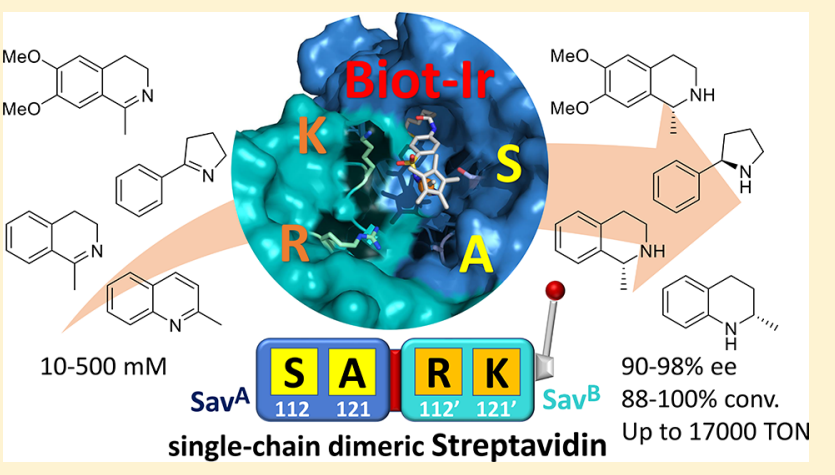
based ArMs. The versatility of scdSav as host protein is highlighted for the asymmetric transfer hydrogenation of prochiral imines using $[\mathrm{Cp} * \operatorname{Ir}($ biot- $p-\mathrm{L}) \mathrm{Cl}]$ as cofactor. By capitalizing on a more precise genetic fine-tuning of the biotin-binding vestibule, unrivaled levels of activity and selectivity were achieved for the reduction of challenging prochiral imines. Comparison of the saturation kinetic data and X-ray structures of $[\mathrm{Cp} * \operatorname{Ir}($ biot- $p$ $\mathrm{L}) \mathrm{Cl}] \cdot \mathrm{scdSav}$ with a structurally related $[\mathrm{Cp} * \operatorname{Ir}($ biot $-p-\mathrm{L}) \mathrm{Cl}] \cdot$ monovalent scdSav highlights the advantages of the presence of a single biotinylated cofactor precisely localized within the biotin-binding vestibule of the monovalent scdSav. The practicality of scdSav-based ArMs was illustrated for the reduction of the salsolidine precursor $(500 \mathrm{mM})$ to afford $(R)$-salsolidine in $90 \%$ ee and $>17000$ TONs. Monovalent scdSav thus provides a versatile scaffold to evolve more efficient ArMs for in vivo catalysis and large-scale applications.

\section{INTRODUCTION}

Artificial metalloenzymes (ArMs) are hybrid catalysts combining attractive features of organometallic catalysts (e.g., broad range of catalyzed reactions) and enzymes (e.g., genetically evolvable and compatible with a cellular environment). ${ }^{1-12}$ They are often created by incorporation of a synthetic metallocofactor within a protein scaffold. Thanks to the progress in biotechnology, several scaffolds have proven versatile for the assembly and optimization of ArMs. These include, among others, hemeproteins, ${ }^{13-16}$ prolyl oligopeptidase, ${ }^{17,18}$ transcriptional repressor LmrR, ${ }^{19,20}$ carbonic anhydrase, ${ }^{21,22}$ and streptavidin (Sav). ${ }^{23,24}$ Due to the high affinity of biotin for (strept)avidin, ${ }^{25,26}$ this anchoring strategy had been exploited by several groups to produce ArMs that catalyze over a dozen reactions. ${ }^{27-36}$ As pioneered by Whitesides, avidin (Avi) isolated from egg-white was initially selected. For recombinant purposes, however, streptavidin (Sav) is preferred thanks to the following features: (i) it can readily be expressed in high yields in E. coli, ${ }^{37}$ (ii) it is less prone to aggregation, and (iii) its isoelectric point $p \mathrm{I}_{\mathrm{Sav}}=6.4$ compared $p \mathrm{I}_{\mathrm{Avi}}=10.4$. Both Avi and Sav are homotetrameric proteins consisting of a dimer of dimers, where the two neighboring subunits are related by a $\mathrm{C}_{2}$ axis. In the past 15 years, more than $20 \mathrm{X}$-ray structures of
Sav-based ArMs have been reported. ${ }^{9,24,31-34}$ Inspection of the biotin-binding vestibule, where the catalytic moiety resides, reveals a narrow distribution of biotinylated metals in the immediate proximity of the $C_{2}$ axis relating the two Sav monomers that make up the biotin-binding vestibule, Figure 1a. Importantly, any point mutation is reflected in all four subunits of homotetrameric Sav, Figure 1b. This symmetryrelationship imposes a significant limitation for the genetic optimization of Sav-based ArMs. Indeed, inspection of the biotin-binding vestibule (Figure 1a) highlights the proximity of biotinylated cofactors to the two symmetry-related S112 and K121 residues. Accordingly, any mutation of these residues is reflected in both Sav monomers (designated $\mathrm{Sav}^{\mathrm{A}}$ and $\mathrm{Sav}^{\mathrm{B}}$ hereafter), thus challenging a precise genetic fine-tuning of the ArM's performance: it is hard to decipher which of the two symmetry-related mutations (i.e., $\mathrm{Sav}^{\mathrm{A}}$ or $\mathrm{Sav}^{\mathrm{B}}$ ) affects (most) the catalytic performance.

An additional challenge concerns the catalytic performance as a function of cofactor occupancy within Sav. Indeed, some ArMs display markedly different catalytic performances as a

Received: June 29, 2019

Published: September 11, 2019 

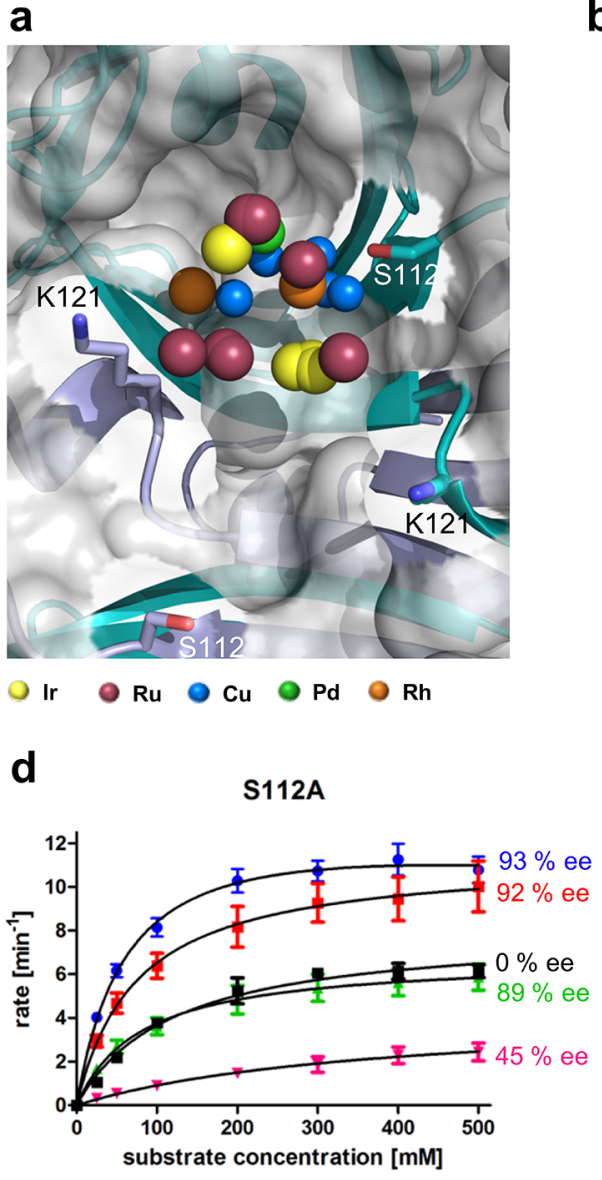

b
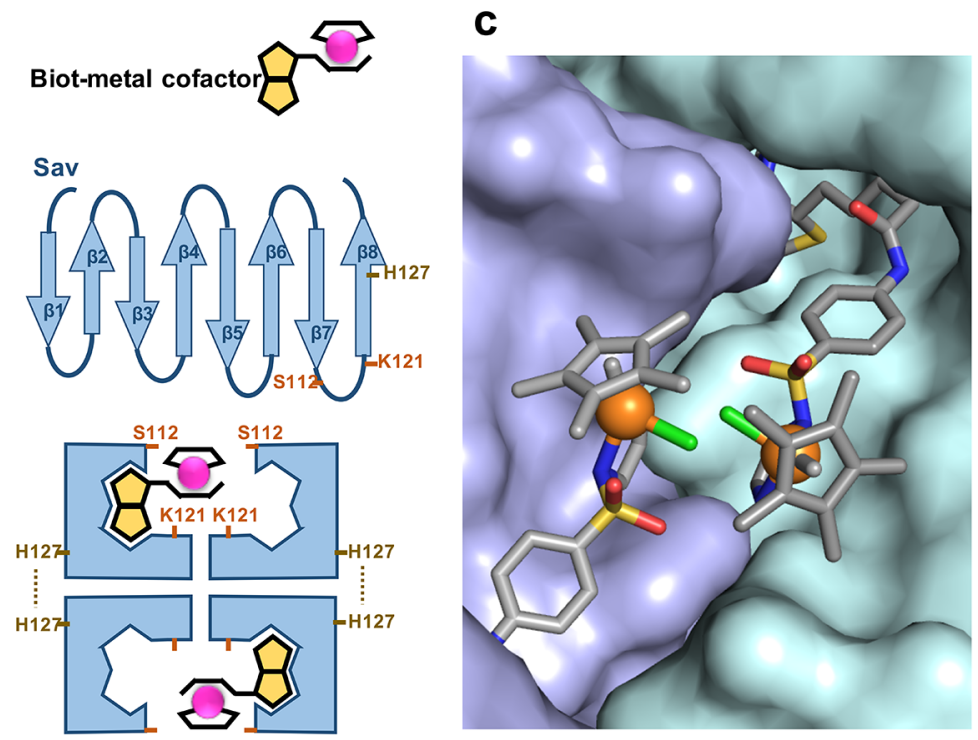

e

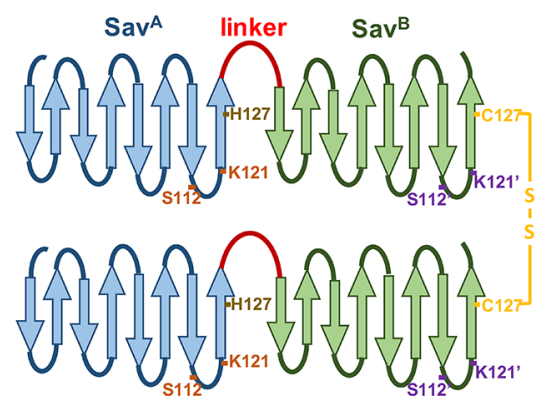

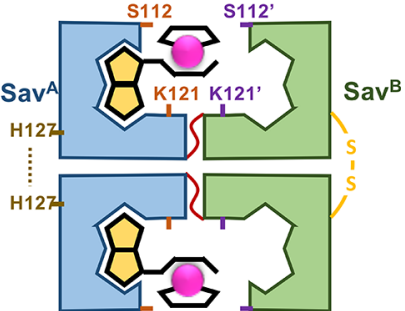

Figure 1. (a) Close-up view of the metal distribution of ArMs based on Sav. Homotetrameric Sav is displayed as surface, residues S112 and K121 of adjacent Sav monomers forming the biotin-binding vestibule are shown as sticks and labeled; the metals from the biotinylated cofactors are represented by spheres: Ir (yellow, PDB codes 6GMI, 6ESS, 6ESU, 4OKA, and 3PK2), Ru (raspberry, PDB codes 6FH8, 5F2B, 5IRA, 2QCB, and 2WPU), $\mathrm{Cu}$ (blue, PDB codes 5VKX, 5VL5, 5VL8, 5WBA, 5WBB, 5WBD, 6ANX, 5WBC, 5K67, 5K68, and 5L3Y), Pd (green, PDB code 5CSE) and $\mathrm{Rh}$ (orange, $\mathrm{PDB}$ codes 4GJV and 4GJS). For clarity, only the metal ions present in the cofactors are shown (spheres, with only one metal per Sav dimer displayed). (b) Cartoon representation of an ArM based on homotetrameric Sav with symmetry-related S112 and K121 in the proximity of the biotinylated cofactor. (c) Close-up view of the X-ray structure of [Cp*Ir(biot- $p$-L)Cl]·Sav S112A (PDB code 3PK2) with all biotin-binding sites occupied. As can be appreciated, severe steric clashes prevent the localization of adjacent cofactors to occupy the same orientation. ${ }^{31}$ The homotetrameric Sav is displayed in surface representation and colored by protein chains. The cofactors are represented as stick models and the Iratom as orange sphere; nitrogen, blue; oxygen, red; sulfur, yellow; chloride, green. (d) Michaelis-Menten kinetics of [Cp* $\operatorname{Ir}($ biot- $p$-L)Cl]·Sav S112A highlighting the marked influence of the cofactor loading on both the activity and the stereoselectivity of the corresponding ATHase. ${ }^{33}$ The initial rates are displayed with respect to the concentration of iridium. [Sav] $=25 \mu \mathrm{M}$ (corresponding to [biotin-binding sites] $=100 \mu \mathrm{M}$ ) was held constant, varying the Ir/Sav ratio from 1.0 (blue data points) to 2.0 (red data points), 3.0 (green data points), and 4.0 (magenta data points). For comparison, the initial rates for the free $[\mathrm{Cp} * \operatorname{Ir}($ biot $-p-\mathrm{L}) \mathrm{Cl}]$ catalyst are displayed $(50 \mu \mathrm{M}$, black data points). The positive ee values correspond to $(R)$-salsolidine. The black solid lines correspond to the fit obtained using the Michaelis-Menten or the Haldane equation. Reprinted in part with permission from ref 33, Copyright 2014 ACS. (e) Design of scdSav relying on the linking of $\mathrm{Sav}^{\mathrm{A}} \mathrm{and} \mathrm{Sav}^{\mathrm{B}}$ via a peptide linker (red line) and introducing a disulfide bond between two scdSavs (yellow line).

function of cofactor:Sav ratio. Upon varying the $[\mathrm{Cp} * \operatorname{Ir}($ biot- $p$ L)Cl]:Sav S112A ratio from one to four, the enantioselectivity of the asymmetric transfer hydrogenase toward the salsolidine precursor 1a erodes from $93 \%$ ee (R)-2a to $45 \%$ ee $(R)-\mathbf{2 a}$, Figure $1 c, d$. In stark contrast, for $[\mathrm{Cp} * \operatorname{Ir}($ biot $-p-\mathrm{L}) \mathrm{Cl}]: \mathrm{Sav}$ $\mathrm{S} 112 \mathrm{~K}$, the enantioselectivity remains by-and-large constant, irrespective of the above ratio (e.g., $70 \%$ ee $(S)-2 a$ vs $78 \%$ ee $(S)$-2a upon varying the ratio from one to four). ${ }^{33}$ The complications are exacerbated by the noncooperative binding of biotinylated cofactors to Sav: adding 2 equiv of biotinylated cofactor vs homotetrameric Sav affords a Poisson distribution of cofactor occupancy. ${ }^{38}$ With in vivo catalysis in mind, whereby the $[\mathrm{Sav}]$ is unknown and highly variable, it is desirable to achieve a precise control of ArM's performance, irrespective of the Sav:cofactor ratio. ${ }^{39-41}$ With these goals in mind, we present herein our efforts toward the engineering of a single chain dimeric streptavidin (scdSav hereafter), enabling the independent mutagenesis of the two neighboring Sav subunits.

\section{RESULTS AND DISCUSSION}

Design of scdSav. Circular permutation strategies have been applied to fuse two subunits of avidin while maintaining high biotin-binding affinity. ${ }^{42,43}$ Circularly permutated Sav has also been reported but with a significantly reduced affinity to biotin. ${ }^{44}$ Initially, we evaluated a similar approach to engineer circularly permutated scdSav. However, these constructs expressed poorly in E. coli $\left(<1 \mathrm{mg} \mathrm{L}^{-1}\right.$ in culture medium), 
Scheme 1. Asymmetric Transfer Hydrogenation of Imines 1a-1e in the Presence of $[\mathrm{Cp} * \operatorname{Ir}(\operatorname{biot}-p-\mathrm{L}) \mathrm{Cl}] \cdot \mathrm{scdSav}{ }^{a}$<smiles>[R]C1=NCCc2cc([R])c([R])cc21</smiles>

1a-1c<smiles>c1ccc(C2=NCCC2)cc1</smiles>

$1 d$<smiles>Cc1ccc2ccccc2n1</smiles>

$1 \mathrm{e}$

$10 \mathrm{mM}$ Conversion $(c)$ [\%]:

[Cp*Ir(biot-p-L)Cl] $25 \mu \mathrm{M}$ scdSav $50 \mu \mathrm{M}$ or Sav $100 \mu \mathrm{M}$

MOPS 0.6M, pH = 7 $\mathrm{HCO}_{2} \mathrm{Na} 3 \mathrm{M}, 25^{\circ} \mathrm{C}, 24 \mathrm{~h}$

1a, 2a: $R_{1}=O M e, R_{2}=M e$

1b, $2 b: R_{1}=H, R_{2}=M e$

1c, 2c: $R_{1}=H, R_{2}=P h$<smiles>[R]c1cc2c(cc1[R])C([R2])NCC2</smiles>

2a-2c<smiles>c1ccc(C2CCCN2)cc1</smiles>

2d<smiles>CC1CCc2ccccc2N1</smiles>

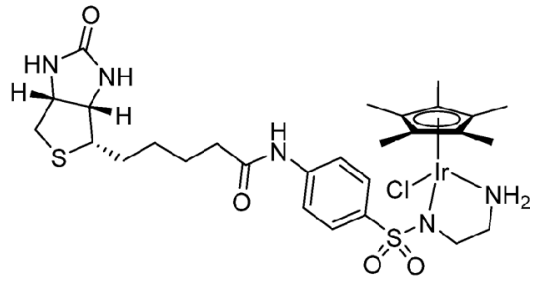

[Cp* $\mid r($ biot-p-L)Cl]

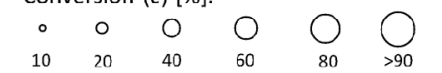

\begin{tabular}{|c|c|c|c|c|c|}
\hline Protein & 1a & $1 \mathrm{~b}$ & $1 c$ & Id & 1e \\
\hline No prot. & 0 & 。 & 。 & 。 & 。 \\
\hline Sav & 0 & 0 & $\circ$ & 0 & - \\
\hline scdSav(SKSK) & 0 & 0 & $\circ$ & - & - \\
\hline $\operatorname{scdSav}(A K S K)$ & & & 0 & 0 & . \\
\hline scdSav(SKAK) & 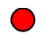 & 0 & $\mathrm{O}$ & 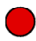 & - \\
\hline scdSav(AKAK) & 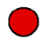 & 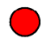 & 0 & 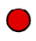 & 。 \\
\hline scdSav(RKSK) & 0 & 0 & 。 & $\bullet$ & 。 \\
\hline scdSav(SKRK) & 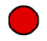 & 0 & 0 & 0 & - \\
\hline scdSav(RKRK) & 0 & o & $\circ$ & $\bullet$ & - \\
\hline $\operatorname{scdSav}($ KKSK) & 。 & o & 。 & 。 & 。 \\
\hline scdSav(SKKK) & 0 & 0 & 0 & • & - \\
\hline $\operatorname{scdSav}($ KKKK) & 。 & 。 & $\circ$ & 。 & 。 \\
\hline
\end{tabular}

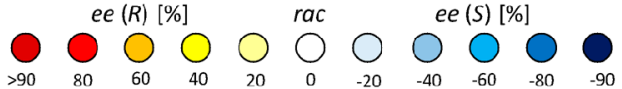

\begin{tabular}{|c|c|c|c|c|c|}
\hline Protein & $1 a$ & $1 \mathrm{~b}$ & $1 c$ & Id & le \\
\hline scdSav(SASK) & & & 0 & 0 & 0 \\
\hline scdSav(AASK) & & & 0 & 0 & 0 \\
\hline scdSav(SAAK) & & & $\bigcirc$ & 0 & ○ \\
\hline scdSav(AAAK) & & & $\checkmark$ & ○ & - \\
\hline $\operatorname{scdSav}($ RASK) & O & & 。 & - & 。 \\
\hline scdSav(SARK) & & & 0 & 0 & $\bullet$ \\
\hline scdSav(RARK) & 0 & ) & 。 & 0 & 。 \\
\hline scdSav(KASK) & o & 0 & $\circ$ & 0 & 。 \\
\hline scdSav(SAKK) & 0 & & 0 & 0 & 0 \\
\hline scdSav(KAKK) & o & 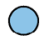 & o & • & 。 \\
\hline $\operatorname{scdSav(SKSA)}$ & 0 & D & 0 & 0 & - \\
\hline scdSav(AKSA) & o & 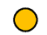 & 0 & 。 & • \\
\hline
\end{tabular}

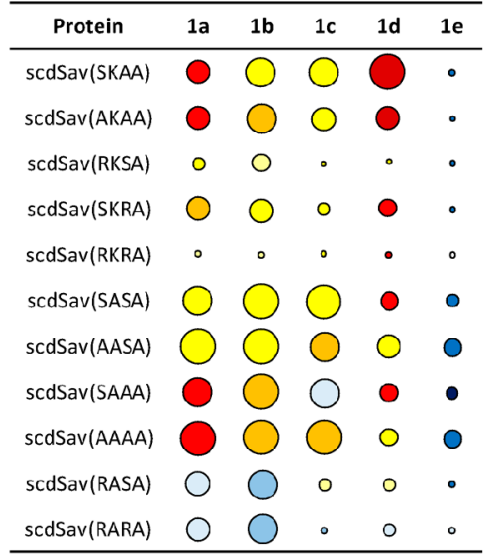

${ }^{a}$ The size of the disk is proportional to the conversion and its color codes for the ee of the corresponding product. Reaction conditions: $10 \mathrm{mM}$ substrate, $25 \mu \mathrm{M}$ [Cp*Ir(biot-p-L)Cl], $50 \mu \mathrm{M}$ scdSav (= $100 \mu \mathrm{M}$ biotin-binding sites), $0.6 \mathrm{M}$ MOPS, $3 \mathrm{M}$ formate, $\mathrm{pH} 7.0,25{ }^{\circ} \mathrm{C}, 24 \mathrm{~h}$.

hampering thorough characterization and practical implementation in biotechnology. We thus set out to fuse the C-terminus of $\mathrm{Sav}^{\mathrm{A}}$ with the $\mathrm{N}$-terminus of $\mathrm{Sav}^{\mathrm{B}}$, Figure 1e. Inspection of the X-ray structure of mature Sav (PDB code $2 \mathrm{BC} 3)^{45}$ reveals that the $\mathrm{C}$ - and $\mathrm{N}$-termini are remote from each other in the quaternary structure. To connect two Sav subunits, a 26 amino acid linker was thus introduced. In addition, the following points were taken into consideration in the design of scdSav: (i) the DNA sequence homology of the two linked-Sav subunits was minimized to facilitate mutagenesis of each Sav subunit independently; (ii) as the H127 residue forms a $\pi$ stacking interaction with its neighboring $\mathrm{H} 127$ residue, it was mutated to $\mathrm{H} 127 \mathrm{C}$ in the $\mathrm{Sav}^{\mathrm{B}}$ to favor the formation of a disulfide bond with an adjacent scdSav. This ensures the precise assembly of two scdSavs into a single quaternary structure (i.e., $(\operatorname{scdSav})_{2}$ ) bearing one disulfide bond and one $\pi-\pi$ stacking interaction between the two remaining histidines $\mathrm{H} 127$ present in the $(\mathrm{scdSav})_{2}$ quaternary structure, Figure 1 e. ${ }^{43,46}$ With these considerations in mind, scdSav was engineered using a 26 aa linker between $\operatorname{Sav}^{\mathrm{A}}$ and $\operatorname{Sav}^{\mathrm{B}}$, with the $\mathrm{H} 127 \mathrm{C}$ mutation in the $\mathrm{Sav}^{\mathrm{B}}$.

To evaluate the suitability of the scdSav design in the context of ArMs, we selected the asymmetric transfer hydrogenation of prochiral imines using $\left[\mathrm{Cp}^{*} \operatorname{Ir}(\right.$ biot- $\left.p-\mathrm{L}) \mathrm{Cl}\right]$ as a test bed (ATHase hereafter). In this context, the nature of the amino acid at position 112 and 121 was repeatedly shown to significantly affect the ATHase performance, both in terms of activity and selectivity. ${ }^{31,33,47,48}$ In contrast to other ArMs based on the biotin-streptavidin technology, ${ }^{9,23,24}$ the catalytic performance of the evolved ATHases was shown to critically depend on the cofactor:biotin-binding site ratio, Figure 1c,d. Building on this knowledge, we engineered 33 scdSavs with mutations at both of the S112 and K121 positions. The two S112 positions were independently mutated to either alanine, lysine or arginine. The two K121 were independently mutated to an alanine residue or kept as a lysine. To simplify the labeling of these variants, a 4-letter code is used hereafter: the first 2 letters code for residues 112 and 121 within the $S_{a v}{ }^{A}$ and the last 2 letters code for residues 112 and 121 in the $\mathrm{Sav}^{\mathrm{B}}$, respectively. Accordingly, scdSav(SKSK) represents the "wild type" scdSav, which includes the 26 aa linker and the H127C mutation in the $\mathrm{Sav}^{\mathrm{B}}$, Figure 1e.

The scdSav(SASK) gene was synthesized and introduced on the pRSFduet-1 plasmid. The other $32 \mathrm{scdSavs}$ were generated by site-directed mutagenesis using the above plasmid. All the 33 scdSavs were overexpressed in E. coli BL21(DE3) using an autoinduction medium and purified by affinity chromatography on an iminobiotin-sepharose matrix (see SI Figure S1 for SDSPAGE analysis, Table S8 for MS data). For all 33 scdSav variants, $10-50 \mathrm{mg}$ of purified protein was obtained from $1 \mathrm{~L}$ 

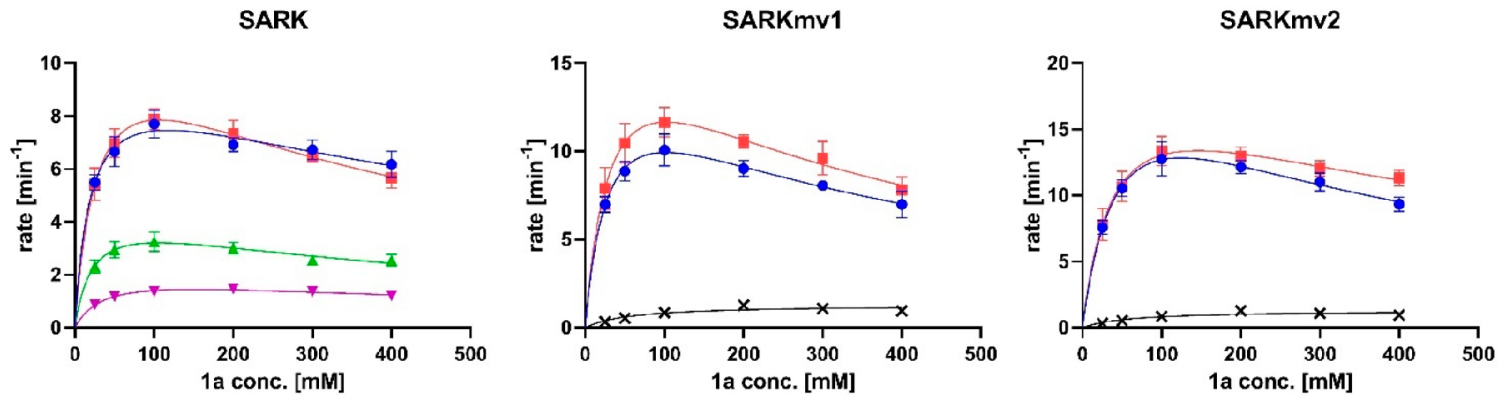

Figure 2. Saturation kinetic data for the reduction of imine 1a with $[\mathrm{Cp} * \operatorname{Ir}($ biot $-p-\mathrm{L}) \mathrm{Cl}] \cdot \operatorname{scdSav}(\operatorname{SARK})$, scdSav $(\mathrm{SARK}) \mathrm{mv} 1$, and $\operatorname{scdSav}(\mathrm{SARK}) \mathrm{mv}$. The reaction rates are normalized to the concentration of $[\mathrm{Cp} * \operatorname{Ir}($ biot- $p$ - $\mathrm{L}) \mathrm{Cl}]$. The $[\mathrm{scdSav}]$ was set at $50 \mu \mathrm{M}$ and [Cp*Ir(biot- $p-\mathrm{L}) \mathrm{Cl}$ ] was varied: $25 \mu \mathrm{M}$ (blue circles), $50 \mu \mathrm{M}$ (red squares), $75 \mu \mathrm{M}$ (green triangles), $100 \mu \mathrm{M}$ (purple triangles). For comparison, the kinetic profile of the free cofactor $[\mathrm{Cp} * \operatorname{Ir}($ biot $-p-\mathrm{L}) \mathrm{Cl}]$ is displayed $(50 \mu \mathrm{M}$, black crosses). Solid lines correspond to the fitting to the Haldane equation (ATHases) or Michaelis-Menten equation (free cofactor). Error bars represent \pm standard deviation.

of culture medium. SDS-PAGE analysis of the purified scdSavs revealed the formation of (scdSav $)_{2}$ (= tetramer of Sav) as the major component, with higher oligomers of scdSav as the minor byproducts (Figure S1). Importantly, all scdSavs maintained their "four equivalents" binding capacity toward biotin-4-fluorescein (B4F).

ATHase Performance of ArMs Based on scdSav. Five prochiral imines $1 \mathbf{1}-\mathbf{e}$ were selected to evaluate the catalytic performance of the engineered $[\mathrm{Cp} * \operatorname{Ir}($ biot- $p-\mathrm{L}) \mathrm{Cl}] \cdot \mathrm{scdSav}$. Three isoquinoline derivatives $(\mathbf{1 a}-\mathbf{1 c})$, a $2 \mathrm{H}$-pyrrole derivative (1d), and quinaldine (1e) were selected as the substrates for the reduction, Scheme 1. With the exception of isoquinoline $1 \mathrm{a}$, these substrates have proven challenging to reduce enantioselectively with ATHases. The results of the ATHase screening for substrates $\mathbf{1 a}-\mathbf{e}$ are summarized in Scheme 1 (see also Table S1). While the free cofactor $[\mathrm{Cp} * \operatorname{Ir}($ biot $-p-\mathrm{L}) \mathrm{Cl}]$ affords the corresponding racemic amines $\mathbf{2 a}-\mathbf{e}$ in low conversion $(1-18 \%)$, incorporation within WT Sav leads to low to moderate conversion (9-68\%) accompanied by modest ee values (30-79\%). Upon substituting WT Sav by scdSav(SKSK), the resulting ATHase activity by-and-large remains the same, both in terms of conversion (14-70\%) and enantioselectivity (42-79\%). Mutagenesis at positions 112 and 121 in both $\mathrm{Sav}^{\mathrm{A}}$ and $\mathrm{Sav}^{\mathrm{B}}$ markedly altered the catalytic performance. To identify important trends, the results were grouped and analyzed according to the amino acids at each specific position (Figure S2). For residue 112 in $\mathrm{Sav}^{\mathrm{A}}$, Ser and Ala clearly outperformed Lys and Arg in terms of conversion for all substrates (Figure $\mathrm{S} 2 \mathrm{a})$. The $112 \mathrm{~S} / \mathrm{A}$ in $\mathrm{Sav}^{\mathrm{A}}$ is also more $(R)$-enantioselective for isoquinoline derivatives $(\mathbf{1 a}-\mathbf{1 c})$ and $(S)$-enantioselective for 1e (Figure S2b). For residue 121 in $\mathrm{Sav}^{\mathrm{A}}$, Ala generally improves the activity while largely maintaining the enantioselectivity for 1a-1c and 1e (Figure S2c,d). The general effects of $112 \mathrm{~S} / \mathrm{A}$ and $121 \mathrm{~A}$ in $\mathrm{Sav}^{\mathrm{A}}$ suggest that they are contributing to the binding of $[\mathrm{Cp} * \operatorname{Ir}($ biot $-p-\mathrm{L}) \mathrm{Cl}]$ in a more productive conformation, in line with a previous computational study of ATHase based on Sav. ${ }^{33}$ On the other hand, no general trends could be deduced for residues 112 and 121 in $\mathrm{Sav}^{\mathrm{B}}$ (Figure $\mathrm{S} 2 \mathrm{e}-\mathrm{h}$ ). The substrate- and context-specific effects of 112 and 121 in $\mathrm{Sav}^{\mathrm{B}}$ suggest that they may contribute to interactions with the substrate and thus fine-tune the activity and enantioselectivity. The best ATHases for each substrate are discussed below. [Cp*Ir(biot- $p-\mathrm{L}) \mathrm{Cl}] \cdot \mathrm{scd} \operatorname{Sav}(\mathrm{SARK})$ reduced imine 1a to amine $(R)-2 \mathrm{a}$ in $100 \%$ conversion (400 TON) and $96 \%$ ee, and imine $\mathbf{1 b}$ to amine $(R)-\mathbf{2 b}$ in $99 \%$ conversion (398
TON) and 93\% ee, respectively. In comparison with the ATHases based on homotetrameric Sav, scdSav(SARK) is similar to the benchmark Sav S112A for (R)-2a (full conversion and $96 \%$ ee at $\left.5{ }^{\circ} \mathrm{C}\right) .{ }^{31}$ For amine $(R)-\mathbf{2 b}$, scdSav(SARK) is markedly more enantioselective than the benchmark SavS112T (full conversion and 59\% ee). ${ }^{49}$ Clearly, the fine-tuned scdSav(SARK) bearing $112 \mathrm{~S}$ and $121 \mathrm{~A}$ in Sav ${ }^{\mathrm{A}}$ and $112 \mathrm{R}$ and $121 \mathrm{~K}$ in $\mathrm{Sav}^{\mathrm{B}}$ outperforms all the homotetrameric Savs tested to date. For the reduction of the bulky substrate 1c, none of the scdSavs exhibited high stereoselectivity (i.e., ee $<70 \%$ ). For the reduction of imine 1 d, $[\mathrm{Cp} * \operatorname{Ir}($ biot- $p-\mathrm{L}) \mathrm{Cl}] \cdot \mathrm{scdSav}(\mathrm{SKAA})$ produced amine $(R)-\mathbf{2 d}$ in $90 \%$ conversion (360 TON) and $98 \%$ ee, outperforming the best ATHase with homotetrameric Sav (68\% conversion and $77 \%$ ee with WT Sav). Such high enantioselectivity (i.e., ee $\geq 95 \%$ ) is challenging to achieve with ArMs. Again, scdSav(SKAA) bearing $112 \mathrm{~S}$ and $121 \mathrm{~K}$ in $\mathrm{Sav}^{\mathrm{A}}$ and $112 \mathrm{~A}$ and $121 \mathrm{~A}$ in $\mathrm{Sav}^{\mathrm{B}}$ outperforms all homotetrameric Savs tested to date. Quinaldine (1e) was only moderately reduced (conversion $<50 \%$ ) by the ATHases under the experimental conditions. Nevertheless, chiral amine $(S)-2$ e was produced in $91 \%$ ee with $[\mathrm{Cp} * \operatorname{Ir}($ biot- $p-\mathrm{L}) \mathrm{Cl}] \cdot \mathrm{scdSav}(\mathrm{SARK})$. In recent years, a number of imine reductase enzymes (IREDs) have been discovered and applied to reduce many cyclic imines to chiral amines with high enantioselectivity. ${ }^{50-52}$ More recently, several IREDs have been found to catalyze reductive amination, ${ }^{53-55}$ i.e., first formation of imines and then reduction to amines, a breakthrough in the enzymatic generation of amines. ATHases have widely been used as a testbed for the development of ArMs. ${ }^{12,31,33,41,48,49}$ In comparison to evolved IREDs recently reported, ATHases typically display more modest catalytic performances.

Engineering a Monovalent scdSav. In light of the high activity and enantioselectivity for the imine reduction, we selected the double mutant $\operatorname{scdSav}(\operatorname{SARK})$ to engineer a monovalent scdSav to investigate the influence of a neighboring cofactor on the catalytic performance of ATHases based on scdSav. Binding of a second biotinylated cofactor in the neighboring Sav subunit often leads to substantial erosion in rate and enantioselectivity. ${ }^{33}$ To determine the biotinbinding stoichiometry of scdSav, a biotin-4-fluorescein (B4F hereafter) titration was performed, relying on the intersection of the two linear segments of the titration curve to determine the binding stoichiometry. ${ }^{56}$ scdSav(SASK) and scdSav(SARK) bind $1.9 \pm 0.1$ and $2.0 \pm 0.1$ B4F per scdSav respectively (Figure S3a,b). To generate a monovalent scdSav, 
Table 1. Saturation Kinetic Parameters and Enantioselectivity for the Reduction of Imine 1a with ATHases Based on scdSav ${ }^{a}$

\begin{tabular}{lccccc}
\multicolumn{1}{c}{ protein } & {$[\mathrm{Cp} * \operatorname{Ir}($ biot- $p$ - $\mathrm{L}) \mathrm{Cl}](\mu \mathrm{M})$} & $(R)-\mathbf{2 a}$ ee $(\%)^{b}$ & $k_{\text {cat }}\left(\mathrm{min}^{-1}\right)^{c}$ & $K_{\mathrm{m}}(\mathrm{mM})$ & $K_{\mathrm{i}}(\mathrm{mM})$ \\
no protein & 50 & 1 & $1.3 \pm 0.1$ & $57 \pm 20$ & n.a. \\
scdSav(SARK) & 25 & 94 & $10.0 \pm 0.8$ & $20 \pm 5$ & $687 \pm 189$ \\
scdSav(SARK) & 50 & 95 & $12.5 \pm 1.2$ & $32 \pm 7$ & $359 \pm 79$ \\
scdSav(SARK) & 75 & 87 & $4.6 \pm 0.6$ & $23 \pm 8$ & $474 \pm 158$ \\
scdSav(SARK) & 100 & 74 & $2.2 \pm 0.3$ & $38 \pm 13$ & $614 \pm 285$ \\
scdSav(SARK)mv1 & 25 & 95 & $16.0 \pm 1.7$ & $31 \pm 7$ & $333 \pm 77$ \\
scdSav(SARK)mv1 & 50 & 96 & $19.8 \pm 2.9$ & $36 \pm 11$ & $294 \pm 89$ \\
scdSav(SARK)mv2 & 25 & 94 & $23.6 \pm 3.0$ & $52 \pm 12$ & $298 \pm 74$ \\
scdSav(SARK)mv2 & 50 & 95 & $21.0 \pm 2.7$ & $42 \pm 11$ & $513 \pm 168$
\end{tabular}

${ }^{a_{T}}$ The reaction conditions are described in Figure 2 . The kinetic parameters were obtained using the Michaelis-Menten and Haldane equations for the free cofactor and the ATHases, respectively. ${ }^{b}$ The ee values were determined after $48 \mathrm{~h}$ with $[\mathbf{1 a}]=25 \mathrm{mM}$. ${ }^{c}$ The $k_{\text {cat }}$ values are normalized to the concentration of $\left[\mathrm{C} \mathrm{p}^{*} \operatorname{Ir}(\right.$ biot $\left.-\mathrm{p}-\mathrm{L}) \mathrm{Cl}\right]$. ${ }^{d} \mathrm{Not}$ available. Error margins represent \pm standard deviation resulting from two independent experiments.

while maintaining the overall topology within the biotinbinding vestibule, two reported sets of mutations were evaluated to knockout the biotin-binding capacity in $\mathrm{Sav}^{\mathrm{B}}$. The following mutants were produced: scdSav(SARK) with additional N23A/S27D in $\operatorname{Sav}^{\mathrm{B}}$ (scdSav(SARK)mv1 hereafter) and scdSav(SARK) with additional N23A/S27D/D128A in $\mathrm{Sav}^{\mathrm{B}}$ (scdSav(SARK)mv2 hereafter). The N23A/S27D and the D128A mutants have been reported to disrupt key H-bonding interactions between Sav and the ureido oxygen and ureido nitrogen by Cantor ${ }^{57}$ and Salemme, ${ }^{58}$ respectively. Gratifyingly, BF4 titration of the resulting scdSav(SARK)mv1 and scdSav(SARK)mv2 revealed the monovalent character of these constructs: $1.1 \pm 0.1$ and $1.2 \pm 0.1$ biotin-binding sites were determined for $\operatorname{scdSav}(\mathrm{SARK}) \mathrm{mv} 1$ and $\operatorname{scdSav}(\mathrm{SARK}) \mathrm{mv} 2$, respectively (Figure $S 3 c, d$ ).

Saturation Kinetics of ATHases Based on scdSav. To gain further insight into the catalytic efficiency of ATHases based on scdSav, we determined the saturation kinetics and enantioselectivity for the reduction of imine 1a to chiral amine $(R)-2 a$ by $\left[\mathrm{Cp}^{*} \operatorname{Ir}(\right.$ biot $\left.-p-\mathrm{L}) \mathrm{Cl}\right] \cdot \operatorname{scdSav}(\mathrm{SARK})$ and its two monovalent variants with varying Ir:scdSav ratios. For all measurements, the concentration of scdSav was kept at $50 \mu \mathrm{M}$, whereas $25,50,75,100 \mu \mathrm{M}[\mathrm{Cp} * \operatorname{Ir}($ biot- $p$-L $) \mathrm{Cl}]$ were used for $\operatorname{scdSav}(\mathrm{SARK})$ (Ir:scdSav ratio $=0.5,1.0,1.5,2.0$ respectively), and 25, $50 \mu \mathrm{M}$ [Cp* $\operatorname{Ir}($ biot- $p-\mathrm{L}) \mathrm{Cl}]$ were used for the monovalent Savs scdSav(SARK)mv1 and scdSav(SARK)mv2 ( Ir:scdSav ratio $=0.5,1.0$ respectively). As summarized in Figure 2 and Table 1, all the ATHases gave rise to high enantioselectivities and pronounced rate-accelerations to afford up to $96 \%$ ee $(R)-2$ a and up to a 10 -fold higher $k_{\text {cat }}$ compared to the free cofactor $[\mathrm{Cp} * \operatorname{Ir}($ biot $-p-\mathrm{L}) \mathrm{Cl}]$. For $\operatorname{scdSav}(\mathrm{SARK})$, capable of binding up to two biotinylated cofactors per scdSav, the reaction rate $\left(k_{\text {cat }}\right)$ markedly decreased and the enantioselectivity was moderately reduced upon increasing the Ir:scdSav beyond one. The erosion of rate and enantioselectivity are in accordance with a previous study of $[\mathrm{Cp} * \operatorname{Ir}($ biot $-\mathrm{p}-\mathrm{L}) \mathrm{Cl}] \cdot \mathrm{Sav} \mathrm{S} 112 \mathrm{~A},{ }^{33}$ suggesting that the binding of an additional $[\mathrm{Cp} * \operatorname{Ir}($ biot- $p-\mathrm{L}) \mathrm{Cl}]$ in the neighboring Sav subunit may cause a significant conformational change of the existing cofactor into a catalytically less favorable conformation. ${ }^{33}$ Because scdSav(SARK)mv1 and scdSav(SARK)mv2 are monovalent, the biotinylated cofactor cannot bind to the second Sav subunit. Thus, no detrimental effects were observed upon increasing the cofactor to protein ratio up to full saturation. In addition, when Ir:scdSav $\leq 1$, a higher reaction rate was observed for monovalent $\operatorname{scdSav}\left(k_{\mathrm{cat}}=\right.$
16.0-23.6 $\left.\mathrm{min}^{-1}\right)$ than that of divalent scdSav $\left(k_{\mathrm{cat}}=10.0-\right.$ $\left.12.5 \mathrm{~min}^{-1}\right)$ and previous homotetrameric Sav S112A $\left(k_{\mathrm{cat}}=\right.$ 11.4-14.1 $\left.\mathrm{min}^{-1}\right) .^{33}$ The superiority of monovalent scdSav may be traced back to the fact that all the bound cofactor resides in a catalytically active conformation for the monovalent scdSav. In contrast, and in light of the noncooperative binding of the cofactor within Sav, even at Ir:scdSav $\leq 1$, a portion of the cofactor $\left[\mathrm{Cp}^{*} \operatorname{Ir}(\right.$ biot $\left.-p-\mathrm{L}) \mathrm{Cl}\right]$ binds in an unproductive conformation, leading to an erosion in rate.

Structural Characterization of scdSav ArMs by X-ray Crystallography. To gain structural insight into the ATHases based on the single chain dimeric streptavidin constructs, both scdSav(SASK) and scdSav(SARK)mv2 were crystallized by sitting drop vapor diffusion $\left(2.5 \mu \mathrm{L} 26 \mathrm{mg} / \mathrm{mL}(\mathrm{scdSav})_{2}\right.$ in 10 $\mathrm{mM}$ sodium phosphate buffer with $150 \mathrm{mM} \mathrm{NaCl}, \mathrm{pH} 7$ was mixed with precipitation buffer $2.5 \mu \mathrm{L}, 2 \mathrm{M}\left(\mathrm{NH}_{4}\right)_{2} \mathrm{SO}_{4}, 0.1 \mathrm{M}$ $\mathrm{Na}$-Acetate, $\mathrm{pH} 4)$. The resulting apo crystals were soaked with excess [Cp* $\operatorname{Ir}($ biot- $p$-L)Cl] (dissolved in DMSO). The soaked yellow crystals were cryoprotected with $25 \%$ glycerol and flash frozen in liquid nitrogen. The structure was solved by molecular replacement using the PDB structure $3 \mathrm{PK} 2$ as a molecular model. Residual electron density in the $F_{\mathrm{o}}-F_{\mathrm{c}}$ map was observed in the biotin-binding pocket and in the biotinbinding vestibule. Anomalous dispersion density was observed in the biotin-binding vestibule. Modeling of cofactor [Cp*Ir(biot- $p-\mathrm{L}) \mathrm{Cl}$ ] into the electron density projected the iridium in the position of the anomalous density peak. The X-ray structures reveal, as anticipated, that $[\mathrm{Cp} * \operatorname{Ir}($ biot $-p-\mathrm{L}) \mathrm{Cl}]$. scdSav(SASK) and [Cp*Ir(biot-p-L)Cl].scdSav(SARK)mv2 differ in their Ir:scdSav ratios. For the biological dimer of $\operatorname{scdSav}(\mathrm{SASK})$ (i.e., $\left.(\operatorname{scdSav}(\mathrm{SASK}))_{2}\right)$, both biotin-binding sites present in the single chain dimer are occupied (i.e., amounting to four cofactors for the functional dimeric assembly (scdSav $\left.)_{2}\right)$, Figure 3a. In stark contrast, the biological dimer of monovalent scdSav(SARK)mv2 (i.e., (scdSav$\left.(\mathrm{SARK}) \mathrm{mv} 2)_{2}\right)$ contains only one $[\mathrm{Cp} * \operatorname{Ir}($ biot $-p-\mathrm{L}) \mathrm{Cl}]$ cofactor per single chain dimer (i.e., two cofactors for the functional dimeric assembly of $\left.(\operatorname{scdSav})_{2}\right)$, Figure $3 b$ (see Figure S18 for the anomalous electron density of the iridium atoms). To accommodate the two cofactors within the biotinbinding vestibule of scdSav(SASK), the neighboring cofactors are forced to adopt two different conformations CI and CII, each with a $50 \%$ occupancy and both in the $\left(S_{\text {Ir }}\right)$ - configuration with a $\mathrm{Cl}^{-}$coordinated to Ir. Severe steric clashes prevent neighboring cofactors from occupying two CI conformations 

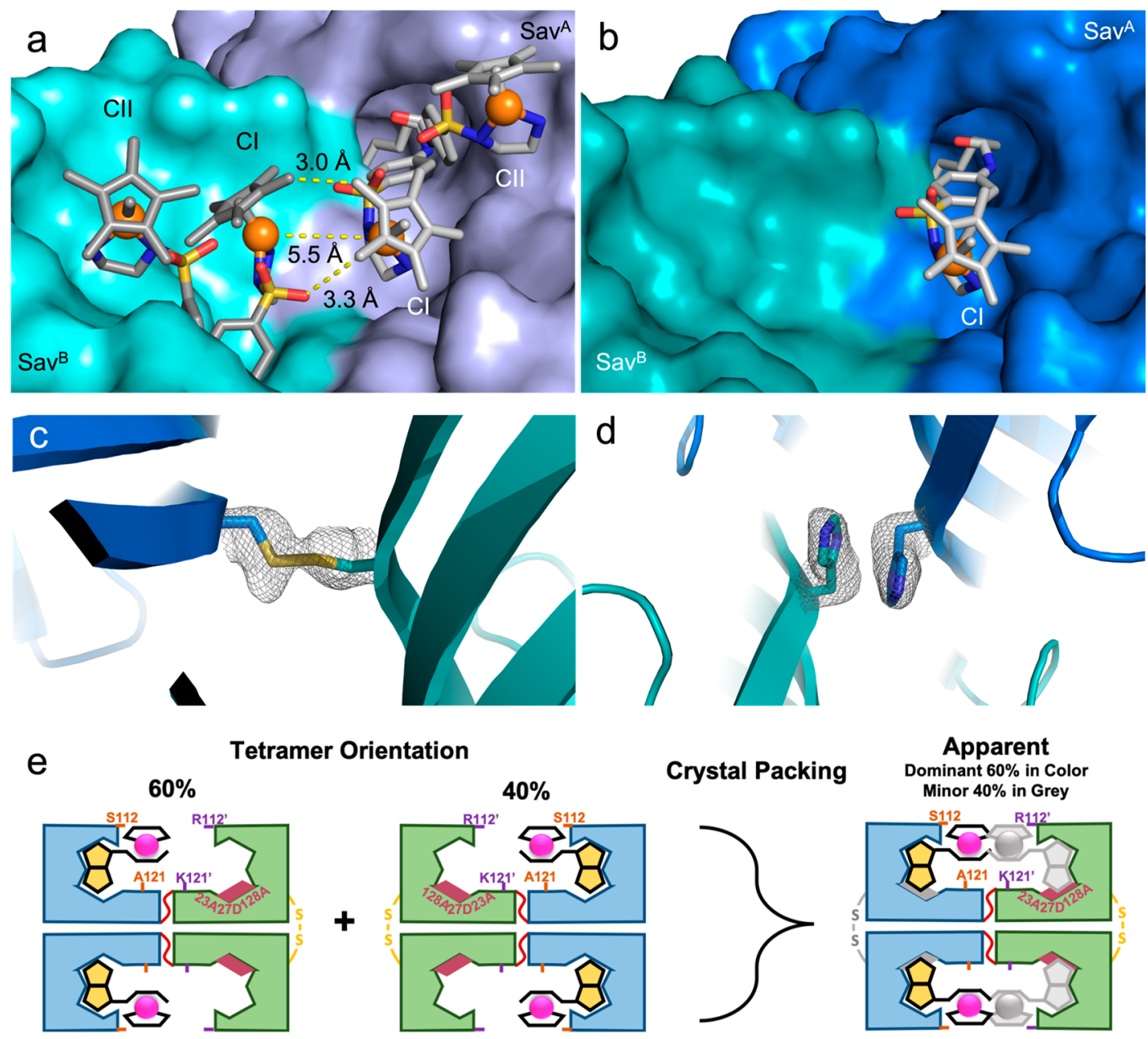

Figure 3. Structural characterization of scdSav(SASK) (a, PDB: 6S4Q) and scdSav(SARK)mv2 (b, PDB: 6S50) with bound [Cp*Ir(biot-p-L)Cl] cofactor. The scdSav proteins are displayed as surface representation and colored by protein chains. The cofactors are represented as stick models and the Ir-atom as orange sphere; nitrogen, blue; oxygen, red; sulfur, yellow. See Figure S21 for stereo view. (a) The two cofactor conformations ( $\mathrm{CI}$ and $\mathrm{CII})$ of $[\mathrm{Cp} * \operatorname{Ir}($ biot- $p-\mathrm{L}) \mathrm{Cl}]$ bound to each binding site are depicted. Both conformations $\mathrm{CI}$ and $\mathrm{CII}$ are occupied at $50 \%$. Selected distances between the two cofactors are highlighted in yellow dashes. (b) For monovalent scdSav(SARK)mv2, only one binding site per (scdSav) is occupied by $[\mathrm{Cp} * \operatorname{Ir}($ biot $-p-\mathrm{L}) \mathrm{Cl}]$. (c,d) The electron density maps $\left(2 F_{\mathrm{o}}-F_{\mathrm{c}}\right.$ at $\left.1 \sigma\right)$ of the residues stabilizing the interactions of a homodimeric

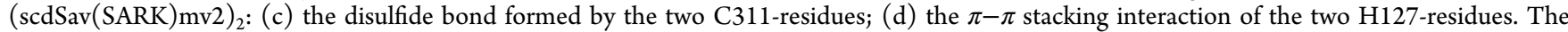
protein is displayed in cartoon mode and colored by protein chain. The interacting amino acids are shown as sticks: nitrogen, blue; sulfur, yellow. (e) Schematic illustration of the (nearly) statistical orientation of crystal packing of [Cp* $\operatorname{Ir}($ biot- $p$-L)Cl] $\cdot s c d S a v(S A R K) m v 2$, reflected in the apparent occupation of both biotin-binding sites, albeit with partial occupancy. The orientation (scdSav) ${ }_{2}$ highlighted in blue in the crystal packing leads to an apparent partial occupation of all four biotin-binding sites, although only the Sav ${ }^{\mathrm{A}}$ site is effectively occupied.

simultaneously, Figure 3a. For $[\mathrm{Cp} * \operatorname{Ir}($ biot- $p$-L)Cl].scdSav(SARK)mv2, only conformation CI is observed with $100 \%$ occupancy with the $\left(S_{\text {Ir }}\right)$-configuration and a $\mathrm{Cl}^{-}$coordinated to Ir (see Figure S19 for an overlay of the cofactors bound to $\operatorname{scdSav}\left(\right.$ SASK) and scdSav(SARK)mv2 and the $2 F_{\mathrm{o}}-F_{\mathrm{c}}$ electron density map of the cofactor). The RMSD of the [Cp* $\operatorname{Ir}($ biot $-p-\mathrm{L}) \mathrm{Cl}]$ cofactor in conformation $\mathrm{CI}$ bound to scdSav(SASK) and scdSav(SARK)mv2 is $0.576 \AA$ (Table S7), suggesting that this is the same conformation. Accordingly, we hypothesize that the first cofactor per scdSav adopts conformation CI, for both scdSav(SASK) and scdSav(SARK)mv2. The second cofactor is forced to adopt conformation CII. Conformation CI of cofactor [Cp* $\operatorname{Ir}($ biot- $p-\mathrm{L}) \mathrm{Cl}]$ observed for scdSav is similar to the binding mode of monomeric streptavidin Sav S112A (PDB: 3PK2) (11 $^{3}$ and Sav S112K (PDB: 4OKA) ${ }^{33}$ with an RMSD of 0.99-1.44 $\AA$ (see Table S7 and Figure S20). Interestingly, the biggest RMSD deviation (1.51 $\AA$, Table S7 and Figure S20) is observed for conformation CII of cofactor [Cp* $\operatorname{Ir}($ biot- $p$-L) Cl] in scdSav(SASK) compared to Sav S112K. This suggests that CII resides in a shallower potential energy well, provided by the protein, than conformation CI.

As can be appreciated in Figure 3a, the protein environment surrounding the two cofactor conformations CI and CII for scdSav(SASK) is markedly different (see also Figure S21 for the stereo view of the environment). As predicted by Maréchal and co-workers, the solvent-exposed CII conformation leads to a decrease in activity and enantioselectivity, see Figure 2.33,59 As the catalytically less efficient conformation CII is not observed in $\left[\mathrm{Cp}^{*} \operatorname{Ir}(\right.$ biot $\left.-\mathrm{p}-\mathrm{L}) \mathrm{Cl}\right] \cdot \mathrm{scdSav}(\mathrm{SARK}) \mathrm{mv} 2$, the corresponding ATHase leads to higher TONs and enantioselectivity for most substrates, Table 2. As modeled for Sav S112A- and Sav S112K-derived ATHases, we speculate that the enantioselectivity is mainly determined by the absolute configuration at Ir. ${ }^{33,59}$ Accordingly, we believe that, as both CI and CII conformations have the same absolute configuration at 
Table 2. Optimization of the Reduction of Dihydroisoquinoline 1a with ATHases Based on scdSav ${ }^{a}$
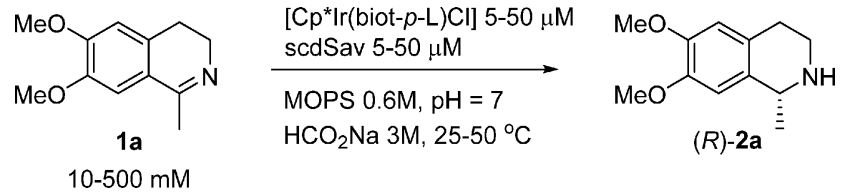

\begin{tabular}{|c|c|c|c|c|c|c|}
\hline protein & {$[\mathrm{Cp} * \operatorname{Ir}($ biot-p-L)Cl] $(\mu \mathrm{M})$} & 1a conc. $(\mathrm{mM})$ & temp. $\left({ }^{\circ} \mathrm{C}\right)$ & conv. (\%) & $(R)-2 \mathbf{a}$ ee $(\%)$ & TON \\
\hline $\operatorname{scdSav}($ SARK) & 5 & 10 & 25 & 95 & 96 & 1910 \\
\hline $\operatorname{scdSav}($ SARK $)$ & 5 & 50 & 25 & 73 & 92 & 7320 \\
\hline $\operatorname{scdSav}($ SARK) & 5 & 100 & 25 & 53 & 90 & 10700 \\
\hline scdSav(SARK) & 5 & 100 & 50 & 78 & 86 & 15600 \\
\hline $\operatorname{scdSav}($ SARK)mv1 & 5 & 100 & 50 & 84 & 89 & 16900 \\
\hline $\operatorname{scdSav}(\mathrm{SARK}) \mathrm{mv} 2$ & 5 & 100 & 50 & 88 & 90 & 17700 \\
\hline $\operatorname{scdSav}(\operatorname{SARK}) \mathrm{mv} 1$ & 50 & $500^{b}$ & 50 & 95 & 87 & 9540 \\
\hline scdSav(SARK)mv2 & 50 & $500^{b}$ & 50 & 95 & 87 & 9510 \\
\hline
\end{tabular}

${ }^{a}$ Reaction conditions: $10-500 \mathrm{mM}$ substrate, 5-50 $\mu \mathrm{M}$ [Cp* $\operatorname{Ir}($ biot- $p-\mathrm{L}) \mathrm{Cl}$ ], 5-50 $\mu \mathrm{M}$ scdSav (= concentration of [Cp* $\operatorname{Ir}($ biot-p-L)Cl]), $0.6 \mathrm{M}$ MOPS, $3 \mathrm{M}$ formate, $\mathrm{pH} 7.0,25-50{ }^{\circ} \mathrm{C}, 48 \mathrm{~h} .{ }^{b} 1 \mathrm{a}(100 \mathrm{mM}$ aliquots) was fed for five consecutive times at $t=0,2,5,10$, and $20 \mathrm{~h}$.

Ir (i.e., $S_{\text {Ir }}$ with a $\mathrm{Cl}^{-}$coordinated to Ir), these preferentially lead to the same enantioenriched amine, albeit with different levels of enantioselectivity.

Although the DNA sequence homology of the fused subunits was minimized to simplify mutagenesis efforts, the amino acid sequence of both subunits is nearly identical: the size, the fold, and the corresponding electron density observed for each subunit of the scdSav are very similar. Accordingly, in the crystal packing, each tetramer can occupy two orientations leading to a mixed electron density. Nonetheless, we observed a preferential orientation of $\operatorname{scdSav}(\mathrm{SASK})$ and scdSav(SARK)mv2 in the crystals resulting in differences for the electron density of N23A/S27D/H127C/D128A and the cofactor binding of $\operatorname{scdSav}(\mathrm{SARK}) \mathrm{mv} 2$. We thus assigned the amino acid sequence according to the dominant electron density observed. The electron density map $\left(2 F_{o}-F_{c}\right)$ of the $\mathrm{H} 127$ and $\mathrm{C} 311$ stabilizing the interaction of the homodimeric $(\operatorname{scdSav}(\operatorname{SARK}) \mathrm{mv} 2)_{2}$ is shown in Figure $3 \mathrm{c}, \mathrm{d}$. The statistical distribution of the tetramer orientation and the resulting mixed structure is depicted in Figure 3e. The 26 amino acid linker between the two subunits could not be modeled as no electron density was observed for these amino acids.

Reaction Optimization and Preparative Scale Synthesis. Having identified the best (scdSav) $)_{2}$ scaffolds for the reduction of imines, we sought to optimize the conditions for the ATHases. For this purpose, the effect of temperature, $\mathrm{pH}$, and substrate concentration were evaluated. For the asymmetric reduction of imine $1 \mathrm{a}, \mathrm{pH}=7.0$ proved best both in terms of conversion and enantioselectivity (Figure S5). Upon increasing the temperature from 25 to $50{ }^{\circ} \mathrm{C}$, higher turnover frequencies (TOF) and TONs were observed, at the cost of a slightly eroded ee (Table 2 and Figure S6). Next, the catalytic potential of $[\mathrm{Cp} * \operatorname{Ir}($ biot $-p-\mathrm{L}) \mathrm{Cl}] \cdot \operatorname{scdSav}(\mathrm{SARK})$ and both its monovalent isoforms were tested (Table 2). At $50{ }^{\circ} \mathrm{C}$ and with [Cp* $\operatorname{Ir}($ biot-p-L)Cl] $(5 \mu \mathrm{M}), \operatorname{scdSav}($ SARK $)(5 \mu \mathrm{M})$ and substrate 1a $(100 \mathrm{mM})$, amine $(R)-2 \mathrm{a}$ is produced in $78 \%$ conversion $($ TON $=15600)$ and $86 \%$ ee. With $[\mathrm{Cp} * \operatorname{Ir}($ biot $-p$ $\mathrm{L}) \mathrm{Cl}] \cdot \mathrm{scdSav}(\mathrm{SARK}) \mathrm{mv2}$, the conversion and the enantioselectivity increases to $88 \%($ TON $=17700)$ and $90 \%$ ee $(R)-2 a$. This TON is significantly higher than that of $\left[\mathrm{Cp}^{*} \operatorname{Ir}(\right.$ biot $-p$ $\mathrm{L}) \mathrm{Cl}] \cdot \mathrm{Sav}$ S112A (TON = 4000). ${ }^{31}$ High substrate loading is often challenging for ATHases. Indeed, for the $\left[\mathrm{Cp}^{*} \operatorname{Ir}(\right.$ biot $-p$ $\mathrm{L}) \mathrm{Cl}] \cdot \operatorname{scdSav}(\mathrm{SARK})$ isoforms, we determined substrate inhibition $\left(K_{\mathrm{i}}=294-687 \mathrm{mM}\right.$, Table 1$)$. To circumvent this challenge, we applied a slow feed of substrate 1a. To our delight, substrate $1 \mathrm{a}(500 \mathrm{mM})$ was reduced to amine $(R)-2 \mathrm{a}$ in $95 \%$ conversion and $87 \%$ ee with $\left[\mathrm{Cp}^{*} \operatorname{Ir}(\right.$ biot $\left.-p-\mathrm{L}) \mathrm{Cl}\right]$. $\operatorname{scdSav}(\mathrm{SARK}) \mathrm{mv} 2(50 \mu \mathrm{M})$ (Table 2, and Figure S7 for the time course). This corresponds to a product concentration of 98.5 g/L, which is similar to the current record of IRED (103.5 $\mathrm{g} / \mathrm{L})$ for the same type of reaction. ${ }^{55}$ A preparative-scale experiment (reaction volume $10 \mathrm{~mL}$ ) was carried out with substrate 1a $(200 \mathrm{mM})$ and $\left[\mathrm{Cp}^{*} \operatorname{Ir}(\right.$ biot $\left.-p-\mathrm{L}) \mathrm{Cl}\right] \cdot \mathrm{scdSav}$ (SARK)mvl $(50 \mu \mathrm{M})$ in a conical flask: $408.2 \mathrm{mg}$ of amine $(R)-2 a$ was isolated in $91 \%$ ee and $98.5 \%$ yield (see Figure S8 for the time course). The same preparative reaction was also performed with [Cp* $\operatorname{Ir}($ biot- $p$-L)Cl] $\cdot \operatorname{scdSav}($ SARK)mv2 (50 $\mu \mathrm{M})$ and $399.3 \mathrm{mg}$ of amine (R)-2a was isolated in $92 \%$ ee and $96.3 \%$ yield (Figure S8). Importantly, essentially pure $(R)$ salsolidine 2 a could be obtained following a simple extraction procedure ( $>95 \%$ purity by ${ }^{1} \mathrm{H}$ NMR, see Figure S16 and S17).

The asymmetric reduction of other prochiral imines $\mathbf{1 b}, \mathbf{1 d}$, and 1e was also investigated, Scheme 2 . By evaluating different loading of $\mathbf{1} \mathbf{b}$ and reaction temperatures (Table S2), we found that imine $\mathbf{1 b}(100 \mathrm{mM})$ was quantitatively reduced to amine $(R)-\mathbf{2 b}$ in $91 \%$ ee with $[\mathrm{Cp} * \operatorname{Ir}($ biot-p-L)Cl] $\cdot \operatorname{scdSav}(\mathrm{SARK})-$

Scheme 2. Optimized Conditions for the Reduction of Prochiral Imines 1b, 1d, and 1e with ATHases Based on scdSav Variants

a)<smiles>CC1=NCCc2ccccc21</smiles>

$$
\begin{aligned}
& \underset{\left[C p^{*} \mid r(\text { biot- } p-L) C l\right] 50 \mu \mathrm{M}}{\text { ScdSav(SARK)mv2 } 50 \mu \mathrm{M}} \\
& \stackrel{\mathrm{MOPS} 0.6 \mathrm{M}, \mathrm{pH}=7}{\longrightarrow} \\
& \mathrm{HCO}_{2} \mathrm{Na} 3 \mathrm{M}, 37^{\circ} \mathrm{C}
\end{aligned}
$$<smiles>c1ccc(C2=NCCC2)cc1</smiles>

[Cp*|r(biot-p-L)Cl] $50 \mu \mathrm{M}$ scdSav(SKAA) $50 \mu \mathrm{M}$

MOPS 0.6M, $\mathrm{pH}=7$ $\mathrm{HCO}_{2} \mathrm{Na} 3 \mathrm{M}, 37^{\circ} \mathrm{C}$ 1d<smiles>Cc1ccc2ccccc2n1</smiles>
$1 e$

[Cp*Ir(biot-p-L)Cl] $50 \mu \mathrm{M}$ scdSav(SARK)mv2 $50 \mu \mathrm{M}$

MOPS 0.6M, $\mathrm{pH}=7$ $\mathrm{HCO}_{2} \mathrm{Na} 3 \mathrm{M}, 50^{\circ} \mathrm{C}$

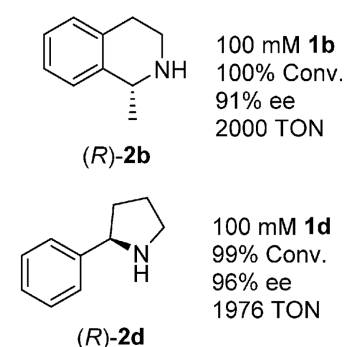

(R)-2d

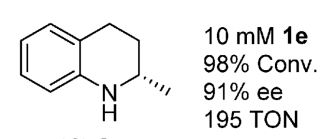

(S)-2e 
mv2 $(50 \mu \mathrm{M})$, corresponding to a TON of 2000 . Similarly, imine 1d $(100 \mathrm{mM})$ was reduced to amine $(R)-2 \mathrm{~d}$ in $99 \%$ conversion and $96 \%$ ee with $[\mathrm{Cp} * \operatorname{Ir}($ biot- $p$-L $) \mathrm{Cl}] \cdot \mathrm{scdSav}-$ (SKAA) $(50 \mu \mathrm{M})$, corresponding to a TON of 1980 (Table S3). Quinaldine (1e) proved challenging to reduce: only $24 \%$ conversion to $(S)$-2e was obtained with $[\mathrm{Cp} * \operatorname{Ir}($ biot $-p-\mathrm{L}) \mathrm{Cl}]$. $\operatorname{scdSav}($ SARK) (Scheme 1). Upon increasing the reaction temperature to $50{ }^{\circ} \mathrm{C}$ and relying on scdSav(SARK)mv2 (Table S4), 98\% conversion (TON = 195) and 91\% ee $(S)-2$ e could be achieved with $50 \mu \mathrm{M}[\mathrm{Cp} * \operatorname{Ir}($ biot- $p$-L)Cl].scdSav(SARK)mv2.

\section{CONCLUSION AND OUTLOOK}

With the aims of expanding the genetic optimization potential as well as resolving the issue related to multiple cofactor binding within the biotin-binding vestibule in ArMs based on the biotin-streptavidin technology, we engineered a singlechain dimeric streptavidin. As both $\operatorname{Sav}^{\mathrm{A}} 112$ and $\mathrm{Sav}^{\mathrm{B}} 112$ residues as well as $\mathrm{Sav}^{\mathrm{A}} 121$ and $\mathrm{Sav}^{\mathrm{B}} 121$ lie in the immediate proximity of the biotinylated metal moiety (Figure 1), the possibility of varying these four critical residues individually (to potentially generate $20^{4}=160000 \mathrm{scdSav}$ mutants) significantly expands the genetic diversity of ArMs based on scdSav. ${ }^{60-62}$ The potential of this strategy was highlighted by evaluating the ATHase activity of 33 different scdSavs toward challenging substrates $\mathbf{1 a - e}$. Gratifyingly, the resulting ATHases outperformed homotetrameric Sav-based ATHases, both in terms of activity (e.g., TON) and selectivity. Further improvements were observed in the presence of monovalent scdSav(SARK)mv1 and scdSav(SARK)mv2. Enzyme kinetics revealed that the monovalent scdSavs outperform the related divalent scdSav for the reduction of substrates $\mathbf{1 a}, \mathbf{1 b}$, and $\mathbf{1 e}$, as the interference of neighboring cofactors is lifted, as highlighted in the X-ray structure of $\left[\mathrm{Cp}^{*} \operatorname{Ir}(\right.$ biot $\left.-p-\mathrm{L}) \mathrm{Cl}\right]$. scdSav(SASK) and $[\mathrm{Cp} * \operatorname{Ir}($ biot $-p-\mathrm{L}) \mathrm{Cl}] \cdot \operatorname{scdSav}($ SARK $) \mathrm{mv} 2$. The practicality of $[\mathrm{Cp} * \operatorname{Ir}($ biot $-p-\mathrm{L}) \mathrm{Cl}] \cdot \mathrm{scdSav}(\mathrm{SARK}) \mathrm{mv} 2$ was illustrated for the reduction of imine $[1 \mathrm{a}]=500 \mathrm{mM}$ to afford salsolidine $(R)-\mathbf{2 a}$ in $90 \%$ ee and $>17000$ TONs. In view of the high recombinant Sav production yields obtained in fed-batch mode (e.g., $>8 \mathrm{~g} / \mathrm{L}$ soluble homotetrameric Sav), ${ }^{37}$ we hope that these findings will contribute to large scale applications of this technology. With in vivo catalysis in mind, ${ }^{39-41,63-65}$ the use of a monovalent scdSav may prove versatile as the catalytic performance of the ArMs is independent of cofactor:Sav ratios. This may also prove useful in other advanced biotechnological applications. ${ }^{66}$

\section{ASSOCIATED CONTENT}

\section{S Supporting Information}

The Supporting Information is available free of charge on the ACS Publications website at DOI: 10.1021/jacs.9b06923.

Experimental procedures, crystallographic data, spectroscopic data, supporting figures and tables (PDF)

\section{AUTHOR INFORMATION}

\section{Corresponding Author}

*thomas.ward@unibas.ch

\section{ORCID}

Shuke Wu: 0000-0003-0914-9277

Yi Zhou: 0000-0003-3467-193X

Johannes G. Rebelein: 0000-0003-2560-716X
Jingming Zhao: 0000-0001-7104-8990

Thomas R. Ward: 0000-0001-8602-5468

\section{Author Contributions}

${ }^{\dagger}$ S.W., Y.Z., and J.G.R. contributed equally.

\section{Notes}

The authors declare no competing financial interest.

\section{ACKNOWLEDGMENTS}

T.R.W. thanks the ERC advanced grant (the DrEAM, grant agreement No. 694424), the Swiss National Science Foundation (Grant SNF 200020_182046) and the NCCR Molecular Systems Engineering for generous support. S.W. thanks the Federal Commission for Scholarships for Foreign Students for an ESKAS Scholarship, and J.G.R. thanks the European Molecular Biology Organisation for a Long-Term fellowship (EMBO ALTF 194-2017). The authors thank Markus Jeschek for preliminary experiments.

\section{REFERENCES}

(1) Schwizer, F.; Okamoto, Y.; Heinisch, T.; Gu, Y.; Pellizzoni, M. M.; Lebrun, V.; Reuter, R.; Kohler, V.; Lewis, J. C.; Ward, T. R. Artificial Metalloenzymes: Reaction Scope and Optimization Strategies. Chem. Rev. 2018, 118, 142-231.

(2) Artificial Metalloenzymes and MetalloDNAzymes in Catalysis: From Design to Applications; Diéguez, M., Bäckvall, J. E., Pàmies, O., Eds.; Wiley-VCH: Weinheim, 2018.

(3) Natoli, S. N.; Hartwig, J. F. Noble-Metal Substitution in Hemoproteins: An Emerging Strategy for Abiological Catalysis. Acc. Chem. Res. 2019, 52, 326-335.

(4) Reetz, M. T. Directed Evolution of Artificial Metalloenzymes: A Universal Means to Tune the Selectivity of Transition Metal Catalysts? Acc. Chem. Res. 2019, 52, 336-344.

(5) Churchfield, L. A.; Tezcan, F. A. Design and Construction of Functional Supramolecular Metalloprotein Assemblies. Acc. Chem. Res. 2019, 52, 345-355.

(6) Roelfes, G. LmrR: A Privileged Scaffold for Artificial Metalloenzymes. Acc. Chem. Res. 2019, 52, 545-556.

(7) Yu, Y.; Liu, X.; Wang, J. Expansion of Redox Chemistry in Designer Metalloenzymes. Acc. Chem. Res. 2019, 52, 557-565.

(8) Lewis, J. C. Beyond the Second Coordination Sphere: Engineering Dirhodium Artificial Metalloenzymes To Enable Protein Control of Transition Metal Catalysis. Acc. Chem. Res. 2019, 52, 576584.

(9) Liang, A. D.; Serrano-Plana, J.; Peterson, R. L.; Ward, T. R. Artificial Metalloenzymes Based on the Biotin-Streptavidin Technology: Enzymatic Cascades and Directed Evolution. Acc. Chem. Res. 2019, 52, 585-595.

(10) Mirts, E. N.; Bhagi-Damodaran, A.; Lu, Y. Understanding and Modulating Metalloenzymes with Unnatural Amino Acids, NonNative Metal Ions, and Non-Native Metallocofactors. Acc. Chem. Res. 2019, 52, 935-944.

(11) Oohora, K.; Onoda, A.; Hayashi, T. Hemoproteins Reconstituted with Artificial Metal Complexes as Biohybrid Catalysts. Acc. Chem. Res. 2019, 52, 945-954.

(12) Raines, D. J.; Clarke, J. E.; Blagova, E. V.; Dodson, E. J.; Wilson, K. S.; Duhme-Klair, A. K. Redox-switchable siderophore anchor enables reversible artificial metalloenzyme assembly. Nat. Catal. 2018, $1,680-688$.

(13) Key, H. M.; Dydio, P.; Clark, D. S.; Hartwig, J. F. Abiological catalysis by artificial haem proteins containing noble metals in place of iron. Nature 2016, 534, 534-537.

(14) Dydio, P.; Key, H. M.; Nazarenko, A.; Rha, J. Y. E.; Seyedkazemi, V.; Clark, D. S.; Hartwig, J. F. An Artificial Metalloenzyme with the Kinetics of Native Enzymes. Science 2016, $354,102-106$. 
(15) Brandenberg, O. F.; Fasan, R.; Arnold, F. H. Exploiting and engineering hemoproteins for abiological carbene and nitrene transfer reactions. Curr. Opin. Biotechnol. 2017, 47, 102-111.

(16) Sreenilayam, G.; Moore, E. J.; Steck, V.; Fasan, R. Metal substitution modulates the reactivity and extends the reaction scope of myoglobin carbene transfer catalysts. Adv. Synth. Catal. 2017, 359, 2076-2089.

(17) Srivastava, P.; Yang, H.; Ellis-Guardiola, K.; Lewis, J. C. Engineering a Dirhodium Artificial Metalloenzyme for Selective Olefin Cyclopropanation. Nat. Commun. 2015, 6, 7789.

(18) Ellis-Guardiola, K.; Rui, H.; Beckner, R.; Srivastava, P.; Sukumar, N.; Roux, B.; Lewis, J. C. Pyrococcus furiosus Prolyl Oligopeptidase: A Dynamic Supramolecular Host for Peptidase and Dirhodium Catalysis. Chemrxiv, 2018. DOI: 10.26434/chemrxiv.7053812.v1

(19) Bos, J.; Browne, W. R.; Driessen, A. J.; Roelfes, G. Supramolecular assembly of artificial metalloenzymes based on the dimeric protein LmrR as promiscuous scaffold. J. Am. Chem. Soc. 2015, 137, 9796-9799.

(20) Drienovská, I.; Mayer, C.; Dulson, C.; Roelfes, G. A designer enzyme for hydrazone and oxime formation featuring an unnatural catalytic aniline residue. Nat. Chem. 2018, 10, 946-952.

(21) Heinisch, T.; Pellizzoni, M.; Durrenberger, M.; Tinberg, C. E.; Kohler, V.; Klehr, J.; Haussinger, D.; Baker, D.; Ward, T. R Improving the Catalytic Performance of an Artificial Metalloenzyme by Computational Design. J. Am. Chem. Soc. 2015, 137, 1041410419 .

(22) Rebelein, J.; Cotelle, Y.; Garabedian, B.; Ward, T. R. Chemical Optimization of Whole-Cell Transfer Hydrogenation Using Carbonic Anhydrase as Host Protein. ACS Catal. 2019, 9, 4173-4178.

(23) Ward, T. R. Artificial Metalloenzymes Based on the BiotinAvidin Technology: Enantioselective Catalysis and Beyond. Acc. Chem. Res. 2011, 44, 47-57.

(24) Heinisch, T.; Ward, T. R. Artificial Metalloenzymes Based on the Biotin-Streptavidin Technology: Challenges and Opportunities. Acc. Chem. Res. 2016, 49, 1711-1721.

(25) Green, N. M. Avidin. In Advances in Protein Chemistry; Anfinsen, C. B., Jr., Edsall, J. T., Richards, F. M., Eds.; Academic Press: New York, 1975; Vol. 29, pp 85-133.

(26) Wilchek, M.; Bayer, E. A. Introduction to avidin-biotin technology. Methods Enzymol. 1990, 184, 5-13.

(27) Wilson, M. E.; Whitesides, G. M. Conversion of a protein to a homogeneous asymmetric hydrogenation catalyst by site-specific modification with a diphosphinerhodium (I) moiety. J. Am. Chem. Soc. 1978, 100, 306-307.

(28) Lin, C.-C.; Lin, C.-C.; Chan, A. S. C. Catalytic Hydrogenation of Itaconic Acid in a Biotinylated Pyrphos-Rhodium(I) System in a Protein Cavity. Tetrahedron: Asymmetry 1999, 10, 1887-1893.

(29) Collot, J.; Gradinaru, J.; Humbert, N.; Skander, M.; Zocchi, A.; Ward, T. R. Artificial Metalloenzymes for Enantioselective Catalysis Based on Biotin-Avidin. J. Am. Chem. Soc. 2003, 125, 9030-9031.

(30) Reetz, M. T.; Peyralans, J. J.-P.; Maichele, A.; Fu, Y.; Maywald, M. Directed Evolution of Hybrid Enzymes: Evolving Enantioselectivity of an Achiral Rh-Complex Anchored to a Protein. Chem. Commun. 2006, 4318-4320.

(31) Dürrenberger, M.; Heinisch, T.; Wilson, Y. M.; Rossel, T.; Nogueira, E.; Knörr, L.; Mutschler, A.; Kersten, K.; Zimbron, M. J.; Pierron, J.; Schirmer, T.; Ward, T. R. Artificial Transfer Hydrogenases for the Enantioselective Reduction of Cyclic Imines. Angew. Chem. Int. Ed. 2011, 50, 3026-3029.

(32) Hyster, T. K.; Knörr, L.; Ward, T. R.; Rovis, T. Biotinylated $\mathrm{Rh}$ (III) Complexes in Engineered Streptavidin for Accelerated Asymmetric C-H Activation. Science 2012, 338, 500-503.

(33) Robles, V. M.; Dürrenberger, M.; Heinisch, T.; Lledós, A.; Schirmer, T.; Ward, T. R.; Maréchal, J.-D. Structural, Kinetic, and Docking Studies of Artificial Imine Reductases Based on BiotinStreptavidin Technology: An Induced Lock-and-Key Hypothesis. J. Am. Chem. Soc. 2014, 136, 15676-15683.
(34) Cotelle, Y.; Lebrun, V.; Sakai, N.; Ward, T. R.; Matile, S. Anion- $\pi$ enzymes. ACS Cent. Sci. 2016, 2, 388-393.

(35) Nödling, A. R.; Świderek, K.; Castillo, R.; Hall, J. W.; Angelastro, A.; Morrill, L. C.; Jin, Y.; Tsai, Y. H.; Moliner, V.; Luk, L. Y. Reactivity and Selectivity of Iminium Organocatalysis Improved by a Protein Host. Angew. Chem., Int. Ed. 2018, 57, 12478-12482.

(36) Olshansky, L.; Huerta-Lavorie, R.; Nguyen, A. I.; Vallapurackal, J.; Furst, A.; Tilley, T. D.; Borovik, A. S. Artificial metalloproteins containing Co4O4 cubane active sites. J. Am. Chem. Soc. 2018, 140, $2739-2742$

(37) Jeschek, M.; Bahls, M. O.; Schneider, V.; Marlière, P.; Ward, T. R.; Panke, S. Biotin-independent strains of Escherichia coli for enhanced streptavidin production. Metab. Eng. 2017, 40, 33-40.

(38) Loosli, A.; Rusbandi, U. E.; Gradinaru, J.; Bernauer, K.; Schlaepfer, C. W.; Meyer, M.; Mazurek, S.; Novic, M.; Ward, T. R. (Strept) avidin as host for biotinylated coordination complexes: stability, chiral discrimination, and cooperativity. Inorg. Chem. 2006, $45,660-668$.

(39) Jeschek, M.; Reuter, R.; Heinisch, T.; Trindler, C.; Klehr, J.; Panke, S.; Ward, T. R. Directed evolution of artificial metalloenzymes for in vivo metathesis. Nature 2016, 537, 661-665.

(40) Okamoto, Y.; Kojima, R.; Schwizer, F.; Bartolami, E.; Heinisch, T.; Matile, S.; Fussenegger, M.; Ward, T. R. A cell-penetrating artificial metalloenzyme regulates a gene switch in a designer mammalian cell. Nat. Commun. 2018, 9, 1943.

(41) Zhao, J.; Rebelein, J. G.; Mallin, H.; Trindler, C.; Pellizzoni, M. M.; Ward, T. R. Genetic Engineering of an Artificial Metalloenzyme for Transfer Hydrogenation of a Self-Immolative Substrate in Escherichia coli's Periplasm. J. Am. Chem. Soc. 2018, 140, 1317113175 .

(42) Nordlund, H. R.; Laitinen, O. H.; Hytönen, V. P.; Uotila, S. T.; Porkka, E.; Kulomaa, M. S. Construction of a dual chain pseudotetrameric chicken avidin by combining two circularly permuted avidins. J. Biol. Chem. 2004, 279, 36715-36719.

(43) Hytönen, V. P.; Hörhä, J.; Airenne, T. T.; Niskanen, E. A.; Helttunen, K. J.; Johnson, M. S.; Salminen, T. A.; Kulomaa, M. S.; Nordlund, H. R. Controlling quaternary structure assembly: Subunit interface engineering and crystal structure of dual chain avidin. J. Mol. Biol. 2006, 359, 1352-1363.

(44) Aslan, F. M.; Yu, Y.; Mohr, S. C.; Cantor, C. R. Engineered single-chain dimeric streptavidins with an unexpected strong preference for biotin-4-fluorescein. Proc. Natl. Acad. Sci. U. S. A. 2005, 102, 8507-8512.

(45) Le Trong, I.; Humbert, N.; Ward, T. R.; Stenkamp, R. E. Crystallographic analysis of a full-length streptavidin with its Cterminal polypeptide bound in the biotin binding site. J. Mol. Biol. 2006, 356, 738-745.

(46) Reznik, G. O.; Vajda, S.; Smith, C. L.; Cantor, C. R.; Sano, T. Streptavidins with intersubunit crosslinks have enhanced stability. Nat. Biotechnol. 1996, 14, 1007-1011.

(47) Mallin, H.; Hestericová, M.; Reuter, R.; Ward, T. R. Library design and screening protocol for artificial metalloenzymes based on the biotin-streptavidin technology. Nat. Protoc. 2016, 11, 835-852.

(48) Hestericová, M.; Heinisch, T.; Alonso-Cotchico, L.; Maréchal, J.-D.; Vidossich, P.; Ward, T. R. Directed Evolution of an Artificial Imine Reductase. Angew. Chem., Int. Ed. 2018, 57, 1863-1868.

(49) Köhler, V.; Wilson, Y. M.; Dürrenberger, M.; Ghislieri, D.; Churakova, E.; Quinto, T.; Knörr, L.; Häussinger, D.; Hollmann, F.; Turner, N. J.; Ward, T. R. Synthetic Cascades are Enabled by Combining Biocatalysts with Artificial Metalloenzymes. Nat. Chem. 2013, 5, 93-99.

(50) Mangas-Sanchez, J.; France, S. P.; Montgomery, S. L.; Aleku, G. A.; Man, H.; Sharma, M.; Ramsden, J. I.; Grogan, G.; Turner, N. J. Imine reductases (IREDs). Curr. Opin. Chem. Biol. 2017, 37, 19-25.

(51) Patil, M. D.; Grogan, G.; Bommarius, A.; Yun, H. Oxidoreductase-catalyzed synthesis of chiral amines. ACS Catal. 2018, 8, 10985-11015.

(52) Velikogne, S.; Resch, V.; Dertnig, C.; Schrittwieser, J. H.; Kroutil, W. Sequence-Based In-silico Discovery, Characterisation, and 
Biocatalytic Application of a Set of Imine Reductases. ChemCatChem

2018, 10, 3236-3246.

(53) Aleku, G. A.; France, S. P.; Man, H.; Mangas-Sanchez, J.; Montgomery, S. L.; Sharma, M.; Leipold, F.; Hussain, S.; Grogan, G.; Turner, N. J. A reductive aminase from Aspergillus oryzae. Nat. Chem. 2017, 9, 961-969.

(54) France, S. P.; Howard, R. M.; Steflik, J.; Weise, N. J.; MangasSanchez, J.; Montgomery, S. L.; Crook, R.; Kumar, R.; Turner, N. J. Identification of novel bacterial members of the imine reductase enzyme family that perform reductive amination. ChemCatChem 2018, 10, 510-514.

(55) Bornadel, A.; Bisagni, S.; Pushpanath, A.; Montgomery, S. L.; Turner, N. J.; Dominguez, B. Technical Considerations for Scale-Up of Imine Reductase Catalyzed Reductive Amination: A Case Study. Org. Process Res. Dev. 2019, 23, 1262-1268.

(56) Kada, G.; Falk, H.; Gruber, H. J. Accurate measurement of avidin and streptavidin in crude biofluids with a new, optimized biotin-fluorescein conjugate. Biochim. Biophys. Acta, Gen. Subj. 1999, 1427, 33-43.

(57) Reznik, G. O.; Vajda, S.; Sano, T.; Cantor, C. R. A streptavidin mutant with altered ligand-binding specificity. Proc. Natl. Acad. Sci. U. S. A. $1998,95,13525-13530$.

(58) Weber, P. C.; Ohlendorf, D. H.; Wendoloski, J. J.; Salemme, F. R. Structural origins of high-affinity biotin binding to streptavidin. Science 1989, 243, 85-88.

(59) Muñoz Robles, V.; Vidossich, P.; Lledós, A.; Ward, T. R.; Maréchal, J.-D. Computational Insights on an Artificial Imine Reductase Based on the Biotin-Streptavidin Technology. ACS Catal. 2014, 4, 833-842.

(60) Hyster, T. K.; Ward, T. R. Genetic Optimization of Metalloenzymes: Enhancing Enzymes for Non-Natural Reactions. Angew. Chem., Int. Ed. 2016, 55, 7344-7357.

(61) Markel, U.; Sauer, D. F.; Schiffels, J.; Okuda, J.; Schwaneberg, U. Towards the Evolution of Artificial Metalloenzymes-A Protein Engineer's Perspective. Angew. Chem., Int. Ed. 2019, 58, 4454-4464.

(62) Arnold, F. H. Directed evolution: bringing new chemistry to life. Angew. Chem., Int. Ed. 2018, 57, 4143-4148.

(63) Rebelein, J. G.; Ward, T. R. In vivo catalyzed new-to-nature reactions. Curr. Opin. Biotechnol. 2018, 53, 106-114.

(64) Bose, S.; Ngo, A. H.; Do, L. H. Intracellular transfer hydrogenation mediated by unprotected organoiridium catalysts. $J$. Am. Chem. Soc. 2017, 139, 8792-8795.

(65) Soldevila-Barreda, J. J.; Metzler-Nolte, N. Intracellular Catalysis with Selected Metal Complexes and Metallic Nanoparticles: Advances toward the Development of Catalytic Metallodrugs. Chem. Rev. 2019, $119,829-869$.

(66) Osuna Gálvez, A.; Bode, J. W. Traceless Templated AmideForming Ligations. J. Am. Chem. Soc. 2019, 141, 8721-8726. 